\title{
Distribution and related factors of corneal regularity and posterior corneal astigmatism in cataract patients
}

This article was published in the following Dove Press journal: Clinical Ophthalmology

\section{Chen Li \\ Jiaju Zhang \\ Xue Yin \\ Jianqing $\mathrm{Li}$ \\ Yihong Cao \\ Peirong Lu}

Department of Ophthalmology, The First Affiliated Hospital of Soochow University, Suzhou, People's Republic of China
Correspondence: Peirong Lu

Department of Ophthalmology, The First Affiliated Hospital of Soochow University, Shizi Street 188, Suzhou 21006, Jiangsu

Province, People's Republic of China

Tel +865 I26521 519|

Email lupeirong@suda.edu.cn
Purpose: To study the distribution of posterior corneal astigmatism (PCA) and its influencing factors in Chinese patients before cataract surgery.

Patients and methods: A retrospective study was conducted in the First Affiliated Hospital of Soochow University, Suzhou, China. In all, this study enrolled 121 eligible eyes of 121 cataract patients. The astigmatism, aberrations and $\mathrm{Q}$ value of anterior, posterior and total cornea and anterior segment parameters (ACD, CCT, WTW, ATA) were measured by the Sirius System, and AL was measured by Lenstar LS 900. Cataract was diagnosed using slit-lamp examination.

Results: The mean age of patients was $67.44 \pm 10.66$ years old. Mean PCA was $0.31 \pm 0.17$ (range 0.05-1.09) D and 85.9\% eyes had PCA values $<0.5 \mathrm{D}$. With-the-rule (WTR) astigmatism predominated the anterior cornea astigmatism (ACA) (48.8\%) and total corneal astigmatism (TCA) (61.2\%), while against-the-rule (ATR) astigmatism predominated posterior $(86.0 \%)$. Significant positive correlation was found between the astigmatic power vector (APV) of ACA and PCA (Pearson correlation=0.318, $P<0.001$ ); TCA and PCA (Pearson correlation=0.204, $P=0.025$ ); keratometric astigmatism and PCA (Pearson correlation $=0.356$, $P<0.001)$; this study also found a positive correlation between primary spherical aberration $\left(\mathrm{Z}^{\circ}\right)$ of the total cornea and PCA (Pearson correlation=0.266, $P=0.003$ ); primary spherical aberration $\left(\mathrm{Z} 4^{\circ}\right)$ of the corneal front surface and PCA (Pearson correlation=0.260, $P=0.004$ ); total corneal aberrations (Total cornea root mean square [RMS]) and PCA (Pearson correlation=0.327, $P<0.001$ ); total corneal higher-orderaberrations (Total HOA RMS) (Pearson correlation=0.232, $P=0.011$ ); total corneal lower-order aberrations (Total LOA RMS) (Pearson correlation=0.250, $P=0.006$ ). A positive linear correlation between $\mathrm{Q}$ value of corneal front surface and PCA, either $6 \mathrm{~mm}$ pupil diameter (Pearson correlation=0.264, $P=0.003$ ) or $8 \mathrm{~mm}$ pupil diameter (Pearson correlation=0.184, $P=0.043$ ) was found in this study.

Conclusion: Corneal aberration, Q value (front surface specifically) was essential that we need to take into consideration when we conduct PCA and intraocularlens measurement in clinics.

Keywords: astigmatism, posterior corneal astigmatism, aberrations, Q value, Sirius, Scheimpflug photography

\section{Introduction}

Cataract surgery has developed from blindness prevention surgery to refractive surgery. $30-54.9 \%$ of cataract patients have been found a corneal astigmatism of 1 diopter (D) or greater before surgery. ${ }^{1-4}$ If this part of astigmatism is not treated, the 
residual astigmatism after surgery will reduce the uncorrected visual acuity of patients, affecting the postoperative visual clarity. The anterior corneal surface has strong refractive power and is also the main component of corneal astigmatism. The posterior cornea surface was assumed to induce minimal refractive astigmatism, ${ }^{5}$ hence only the anterior corneal surface was usually measured. Recent studies on total corneal astigmatism (TCA) however implicate both anterior and posterior corneal surfaces, suggesting potential astigmatic treatment calculation errors, if posterior corneal astigmatism (PCA) is disregarded. ${ }^{6,7}$ Koch et al found TCA value is affected by PCA (average-0.3D). ${ }^{8}$ PCA potentially decreased TCA in with-the-rule (WTR) astigmatism cases or increased it, as observed in againstthe-rule (ATR) cases ${ }^{1,8-10}$; discounting PCA could result in miscalculated astigmatism, as in WTR cases overestimated by $0.5-0.6 \mathrm{D}$ and ATR underestimated by about $0.2-0.3 \mathrm{D} .^{5}$ A $7.4^{\circ} \pm 10.3^{\circ}$ axis error has also been documented, reportedly caused by ignoring PCA. ${ }^{11}$ Therefore, the posterior corneal surface should also be considered, when evaluating the anterior surface, for astigmatism correction during cataract surgery.

With the advent of light path tracing, real TCA can be measured clinically, and PCA, which was often neglected before, has also been emphasized. Therefore, whether it is for intraocular lens (IOL) measurement or Toric IOL implantation calculation before surgery, it is essential to obtain accurate and personalized PCA before surgery. Corneal topography via Sirius imaging system involves a rapid, repeatable, non-contact, $360^{\circ}$ rotational Scheimpflug camera, and a Placido-disk. Within seconds, the threedimensional camera scans the lens, and maps the anterior and posterior corneal surface topography and elevation, which help with the depth, angle and volume analysis of the anterior chamber; the corresponding keratometer values deliver the wavefront analysis and pachymetric mapping of the entire cornea. ${ }^{12-14}$ Parameters such as keratometry $(\mathrm{K})$ value, central corneal thickness (CCT), anterior chamber depth (ACD), horizontal corneal diameter (WTW), angle to angle distance (ATA), astigmatism value, wavefront aberrations and $\mathrm{Q}$ value are obtained in one measurement. The Sirius Scheimpflug-Placido tomographer is routinely deployed in research as well as clinical use, and preceding studies that measured anterior segment parameters confirm high repeatability and reproducibility. ${ }^{15,16}$ Its repeatability was similar to that reported for Pentacam. ${ }^{17}$ Data that can be considered interchangeable between two instruments including the simulated $\mathrm{K}$; the posterior corneal power; the distance between the corneal endothelium and the $\mathrm{Q}$ value. ${ }^{18}$

Research has already substantiated PCA as significant to TCA, and in postoperative residual refractive errors as well, especially with reference to Toric IOL implanted patients. But posterior cornea characteristics, as influencing factors in cataract patients, still require thorough investigation. Hence, this research on Chinese cataract patients analyzes posterior cornea biometry in detail. It mainly analyzed the magnitude and axial distribution of PCA in middle-aged and elderly cataract patients, and the relationship between it and anteriorcornea astigmatism (ACA), TCA and simulated corneal astigmatism (keratometricastigmatism; KA), as well as the possible influencing factors such as age, axial length (AL), ACD, CCT, WTW, ATA, higher-order aberrations (HOAs) and Q value.

\section{Patients and methods}

This retrospective study recruited patients scheduled for cataract surgery, from July 31, 2017 to May 31, 2018, at the First Affiliated Hospital of Soochow University, Suzhou, China. Any patient with a history of glaucoma, uveitis, dry eye or corneal disease, who may have had ocular surgeries, or even wore contact lenses, within the preceding 2-week period was excluded.

The current research used the Lenstar (Lenstar LS 900, Haag-Streit AG, Koeniz, Switzerland) to measure the AL and Sirius (Sirius, CSO Inc, Florence, Italy) system to measure the ACA, PCA, TCA, KA, AL, ACD, CCT, WTW, ATA, aberration and Q value, all the astigmatism measurements were performed in zone $3 \mathrm{~mm}$ in diameter centered at the corneal center of the eyes, the aberration in pupillary areas of 6-mm analyzed included the root mean square (RMS) values of primary spherical aberration $\left(\mathrm{Z} 4^{\circ}\right)$, primary coma aberration $\left(\mathrm{Z}^{1,-1}\right)$, primary trefoil aberration $\left(\mathrm{Z}^{3,-3}\right)$ of the total cornea, corneal front surface, and corneal back surface, total corneal aberrations (Total cornea RMS), total corneal lower-order aberrations (Total LOA RMS), total corneal HOAs (Total HOA RMS). The $Q$ value includes the $Q$ value of 6 and $8 \mathrm{~mm}$ pupil diameter on the anterior and posterior corneal surface.

Qualified doctors examined the subjects; the focus was on eliminating examiner bias. If measurements seemed beyond instruments limits, patients were re-examined as many times as necessary; excellent data and picture reproducibility ensured the most precise readings, which were then chosen for the study. ACA and TCA axis were 
classified as WTR when the corneal surface steep meridian was $60-120^{\circ}$ and ATR when $0-30^{\circ}$ or $150-180^{\circ}$, corresponding to earlier studies. Conversely, with its characteristic negative posterior surface, PCA was specified as WTR with a $0-30^{\circ}$ or $150-180^{\circ}$ steeped meridian, and ATR for a $60-120^{\circ}$ incline. Residual values classified as oblique astigmatism.

Vector astigmatism analyses were conducted using the method proposed by Thibos ${ }^{19,20}$ for TCA, ACA, PCA and TA according to the following equations:

I) Vector along the $0-$ degree meridian $\left(\mathrm{J}_{0}\right)=$ $[-($ Ksteep - Kflat $) / 2] \times \cos 2 \alpha ;$

II) Vector along the 45 - degree meridian $\left(\mathrm{J}_{45}\right)=$ $[-($ Ksteep - Kflat $) / 2] \times \operatorname{sen} 2 \alpha ;$

III) Astigmatic power vector $($ APV $)=\left(\mathrm{J}_{0}^{2}+\mathrm{J}_{45^{2}}\right)^{1 / 2}$.

The above-mentioned calculations were performed using Microsoft Excel (version 14.4.7; Microsoft Corporation, Redmond, WA, USA), after applying the astigmatism formula I), II), and III), $\mathrm{J}_{0}, \mathrm{~J}_{45}$ and APV are obtained, respectively.

\section{Statistical analysis}

This study used SPSS Statistics version 25.0 (IBM/SPSS, Inc., Chicago, IL, USA) for statistical analysis. Frequency $(\%)$, and mean and $\mathrm{SD}$ (mean $\pm \mathrm{SD}$ ) were respectively deployed for analyses of qualitative and quantitative variables. Pearson's correlation and regression analysis helped assess the TCA, ACA and PCA, aberrations, KA, age, Q value, CCT, ACD, AL, ATA and WTW correlations; statistical significance was set at $P \leq 0.05$.

\section{Results}

This study included a total of 121 eyes of 121 cataract patients, which qualified as per measurements. Table 1 summarizes the study of population demographics. The PCA mean value was set as $0.31 \pm 0.17 \mathrm{D}$. ACA $(69.4 \%)$ and TCA $(64.5 \%)$ figures were predominantly $<1.0 \mathrm{D}$, while most PCA $(57.0 \%)$ values ranged from 0.2 to $0.5 \mathrm{D}$ (Figure 1). The average axes of PCA were $77.65^{\circ} \pm 74.40^{\circ}$, $86.0 \%$ were ATR astigmatism, 8.3\% were astigmatism with the rule, and the rest were oblique astigmatism (Figure 2). Unlike PCA, WTR astigmatism predominates the ACA (48.8\%) and TCA (61.2\%) (Figure 3).

Next, we studied the related factors of PCA, in this section, all astigmatisms and KA were evaluated by vector analysis, the APV was calculated and a linear regression analysis presented ACA and PCA magnitudes as positively correlated (Pearson correlation $=0.318, P<0.001$ ); TCA and PCA (Pearson correlation $=0.204, P=0.025$ ); KA and PCA (Pearson correlation $=0.356, P<0.001$ ) (Figure 4).

PCA (Pearson correlation=0.266, $P=0.003$ ) positively correlated with total corneal primary spherical aberration $\left(\mathrm{Z}^{\circ}\right)$ as well; primary spherical aberration $\left(\mathrm{Z}^{\circ}\right)$ of the corneal front surface and PCA (Pearson correlation=0.260, $P=0.004)$; total corneal aberrations (Total cornea RMS) and PCA (Pearson correlation=0.327, $P<0.001$ ); total corneal HOAs (Total HOA RMS) (Pearson correlation=0.232, $P=0.011$ ); total corneal LOA (Total LOA RMS) (Pearson correlation=0.250, $P=0.006$ ) (Figure 5). However, neither correlations were found between primary spherical aberration of the corneal back surface and PCA, nor primary coma aberration $\left(\mathrm{Z3}^{1,-1}\right)$, primary trefoil aberration $\left(\mathrm{Z3}^{3,-3}\right)$ of the total cornea, corneal front surface, and corneal back surface and PCA (Table S1).

Furthermore, we found a positive linear correlation between $\mathrm{Q}$ value of corneal front surface and PCA, either $6 \mathrm{~mm}$ pupil diameter (Pearson correlation=0.264, $P=0.003$ ) or $8 \mathrm{~mm}$ pupil diameter (Pearson correlation=0.184, $P=0.043$ ) (Figure 6); nevertheless, no correlations were found between $Q$ value of corneal back surface and PCA (Figure 7).

This study also analyzed possible factors affecting PCA, including age, AL, ACD, CCT, WTW and ATA, but no correlation was found between them and PCA (Figure 8).

\section{Discussion}

With the increase of the proportion of the elderly and the increase of cataract surgery population, advanced functional IOL such as multifocal and triple-focus IOL and Toric IOL, the applications of which are becoming more and more widespread. PCA has often been neglected in the past clinical applications. But facts show that although the value is small, it is not a fixed value, that is, the distribution of PCA cannot be inferred only by measuring the asphericity of the anterior corneal surface. ${ }^{21-23}$ Disregarding PCA potentially underestimates ATR astigmatism (ATRA) and overestimates WTR astigmatism (WTRA), and owing to the posterior surface's predominant WTR shape that affects the ATRA power, thus correspondingly yield an undercorrected ATRA and over-corrected WTRA. ${ }^{7,10,24,25}$ The measurement errors of corneal refractive power and astigmatism before cataract surgery will lead to inaccurate IOL 
Table I Demographics of study population

\begin{tabular}{|c|c|c|}
\hline \multicolumn{3}{|l|}{ Parameter } \\
\hline \multirow{3}{*}{$\begin{array}{l}\text { Eye/patient (n) } \\
\text { Male/female (n) }\end{array}$} & \multirow{2}{*}{\multicolumn{2}{|c|}{$\begin{array}{l}|2| /|2| \\
58 / 63\end{array}$}} \\
\hline & & \\
\hline & Mean \pm SD & Range \\
\hline Age (years) & $67.44 \pm 10.66$ & $38-92$ \\
\hline $\mathrm{AL}(\mathrm{mm})$ & $24.64 \pm 2.47$ & $21.17-31.94$ \\
\hline $\mathrm{ACD}(\mathrm{mm})$ & $2.72 \pm 0.38$ & $1.83-3.75$ \\
\hline CCT (mm) & $0.54 \pm 0.03$ & $0.48-0.62$ \\
\hline WTW (mm) & $11.35 \pm 0.38$ & $10.50-12.44$ \\
\hline ATA $(\mathrm{mm})$ & $11.53 \pm 0.76$ & $9.88-15.38$ \\
\hline PCA (D) & $0.31 \pm 0.17$ & $0.05-1.09$ \\
\hline Axial & $77.65 \pm 74.40$ & $0-179$ \\
\hline $\mathrm{ACA}(\mathrm{D})$ & $0.87 \pm 0.64$ & $0.08-3.42$ \\
\hline Axial & $84.61 \pm 51.73$ & $2-178$ \\
\hline TCA (D) & $0.97 \pm 0.69$ & $0.17-3.60$ \\
\hline Axial & $86.47 \pm 45.23$ & $1-178$ \\
\hline $\mathrm{KA}(\mathrm{D})$ & $0.84 \pm 0.67$ & $0.04-3.90$ \\
\hline Axial & $86.69 \pm 50.93$ & $1-179$ \\
\hline $\mathrm{Q}$ value $6 \mathrm{~mm}(\mathrm{~A})$ & $-0.10 \pm 0.17$ & $-0.54-0.52$ \\
\hline $\mathrm{Q}$ value $6 \mathrm{~mm}(\mathrm{P})$ & $-0.4 I \pm 0.30$ & $-1.91 \pm 0.17$ \\
\hline $\mathrm{Q}$ value $8 \mathrm{~mm}(\mathrm{~A})$ & $-0.28 \pm 0.14$ & $-0.67 \pm 0.05$ \\
\hline $\mathrm{Q}$ value $8 \mathrm{~mm}(\mathrm{P})$ & $-0.40 \pm 0.20$ & $-1.19 \pm 0.16$ \\
\hline Z3I,-I cornea & $0.37 \pm 0.21$ & $0.03-1.06$ \\
\hline Z33,-3 cornea & $0.3 I \pm 0.20$ & $0.04-0.97$ \\
\hline Z40 cornea & $0.32 \pm 0.13$ & $-0.06-0.80$ \\
\hline $\mathrm{Z3I},-\mid \mathrm{CF}$ & $0.39 \pm 0.20$ & $0.02-0.97$ \\
\hline Z33,-3 CF & $0.34 \pm 0.22$ & $0.00-1.11$ \\
\hline $\mathrm{Z} 40 \mathrm{CF}$ & $0.30 \pm 0.14$ & $-0.14-0.80$ \\
\hline $\mathrm{Z3I},-\mathrm{ICB}$ & $0.09 \pm 0.05$ & $0.02-0.26$ \\
\hline Z33,-3CB & $0.07 \pm 0.06$ & $0.01-0.38$ \\
\hline Z40 CB & $0.02 \pm 0.03$ & $-0.04-0.14$ \\
\hline Total cornea RMS & $1.14 \pm 0.60$ & $0.49-3.97$ \\
\hline Total HOA RMS & $0.82 \pm 0.65$ & $0.07-3.94$ \\
\hline Total LOA RMS & $0.69 \pm 0.28$ & $0.32-2.00$ \\
\hline
\end{tabular}

Notes: $Q$ value $6 \mathrm{~mm}(\mathrm{~A})=\mathrm{Q}$ value of anterior corneal surface under $6 \mathrm{~mm}$ pupil diameter, $\mathrm{Q}$ value $6 \mathrm{~mm}(\mathrm{P})=\mathrm{Q}$ value of posterior corneal surface under $6 \mathrm{~mm}$ pupil diameter, $Q$ value $8 \mathrm{~mm}(\mathrm{~A})=\mathrm{Q}$ value of anterior corneal surface under $8 \mathrm{~mm}$ pupil diameter, $\mathrm{Q}$ value $8 \mathrm{~mm}(\mathrm{P})=\mathrm{Q}$ value of posterior corneal surface under $8 \mathrm{~mm}$ pupil diameter, Z3I,-I cornea = the primary coma aberration of the total cornea, Z33,-3 cornea = primary trefoil aberration of the total cornea, Z40 cornea $=$ primary spherical aberration of the total cornea, Z3I,-I CF = primary coma aberration of the corneal front surfaces, Z33,-3 CF = primary trefoil aberration of the corneal front surfaces, Z40 $\mathrm{CF}=$ primary spherical aberration of the corneal front surfaces, $Z 3 \mathrm{I},-\mathrm{I} C B=$ primary coma aberration of the corneal back surfaces, $Z 33,-3 \mathrm{CB}=$ primary trefoil aberration of the corneal back surfaces, Z40 CB = primary spherical aberration of the corneal back surfaces, Total cornea RMS = the total corneal aberrations, Total $\mathrm{HOA}$ RMS $=$ total corneal higher-order aberrations, Total LOA RMS = total corneal lower-order aberrations.

Abbreviations: AL, axial length; KA, simulated corneal astigmatism; ACA, anterior cornea astigmatism; $A C D$, anterior chamber depth; AL, axial length; APV, astigmatic power vector; ATA, angle to angle distance; ATRA, ATR astigmatism; CCT, central corneal thickness; D, diopter; HOAs, higher-order aberrations; IOL, intraocular lens; K, keratometry; LOA, lower-order aberrations; PCA, posterior corneal astigmatism; RMS, root mean square; TCA, total corneal astigmatism; WTR, with-the-rule; WTRA, WTR astigmatism; WTW, horizontal corneal diameter.

degree in surgery. Especially before Toric IOL implantation, the determination of degree and axis should be combined with the required spherical lens degree, corneal astigmatism value and axis to calculate. The wrong choice of corneal astigmatism will make the model and axis of IOL mismatch with the actual corneal astigmatism. This will inevitably lead to postoperative refractive errors, affecting the visual experience of people after cataract extraction. Therefore, in order to achieve better effect of astigmatism correction, PCA should be quantitatively analyzed when we perform ocular biometry before surgery. With the development of anterior segment examination equipment, there are many kinds of anterior segment analyzers that can directly quantify PCA, such as Pentacam, Orbscan and Sirius. In this 

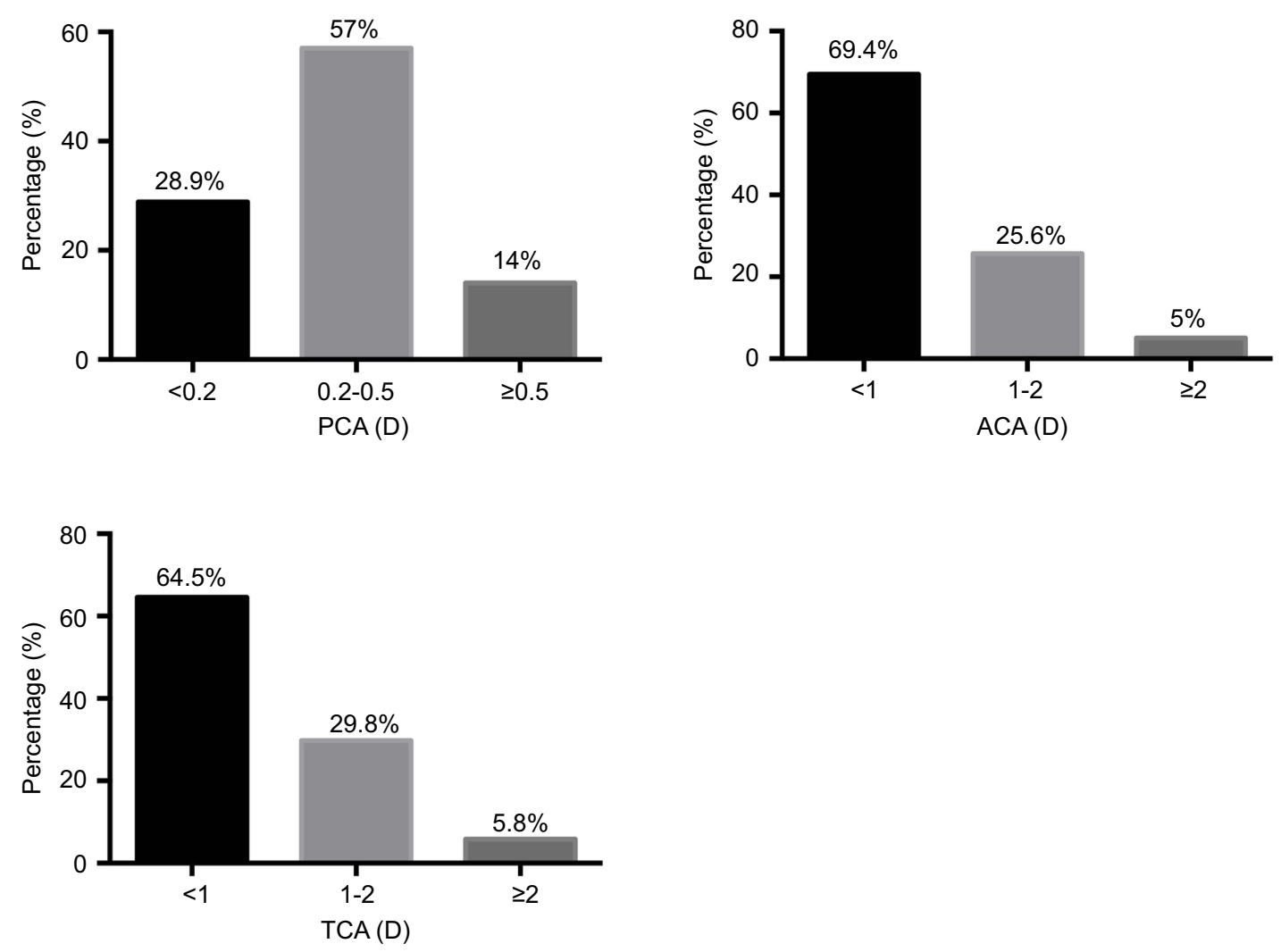

Figure I Distribution of magnitude of PCA, ACA and TCA at 3-mm corneal diameter in cataract patients. Abbreviations: D, diopters; PCA, posterior corneal astigmatism; ACA, anterior corneal astigmatism; TCA, total corneal astigmatism.

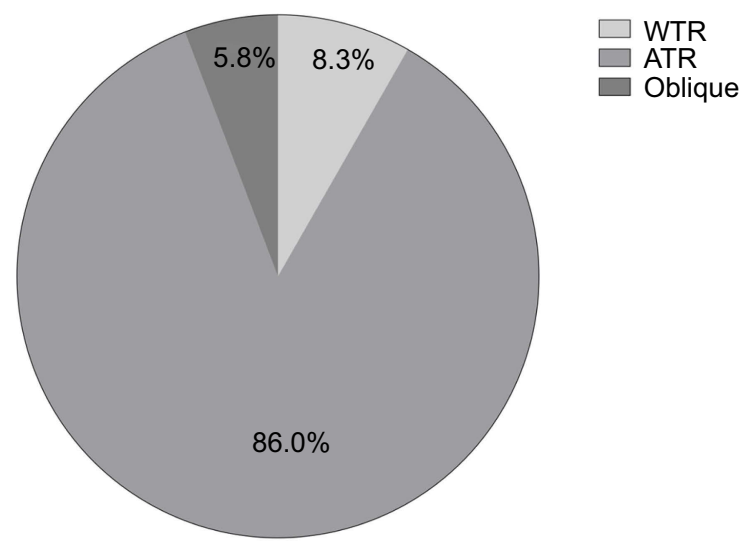

Figure 2 Distribution of axial of PCA at 3-mm corneal diameter.

Abbreviations: PCA, posterior corneal astigmatism; WTR, with-the-rule; ATR, against-the-rule.

study, Sirius anterior segment analysis system was used to calculate the total corneal refractive power, TCA, simulated corneal astigmatism, anterior and posterior surface astigmatism, and so on by light path tracking. PCA can be quantitatively analyzed with high repeatability. $15,26,27$

Wavefront aberration is usually fitted on a specific circular domain. When a specific circular domain changes,

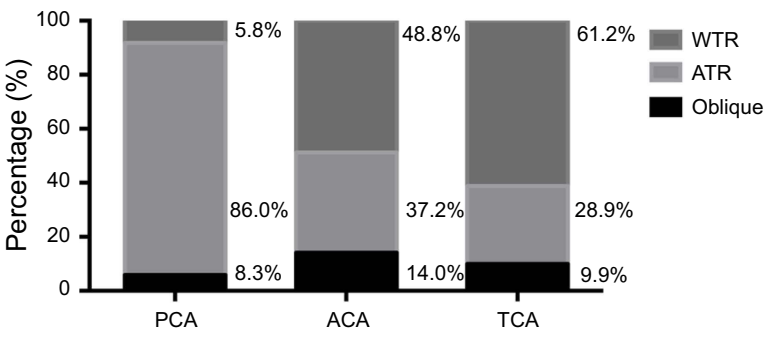

Figure 3 The overall distribution of anterior, posterior, and TCA at 3-mm corneal diameter in cataract patients.

Abbreviations: PCA, posterior corneal astigmatism; ACA, anterior corneal astigmatism; TCA, total corneal astigmatism; WTR, with-the=rule; ATR, against-therule.

the fitted wavefront aberration will also change. Therefore, pupil size plays an important role in the estimation of wavefront aberration. The visual quality is mainly affected by aberration and astigmatism. When the pupil size is $<3$ $\mathrm{mm}$, the aberration is very small. The aberration is generally $<1 / 4$ th of the wavelength of light. Therefore, when the pupil size is in this area, the image quality of the retina is usually not disturbed by aberration and scattering. ${ }^{28}$ With the increase of pupil size, aberration will also increase gradually. At this time, the pupil size becomes 

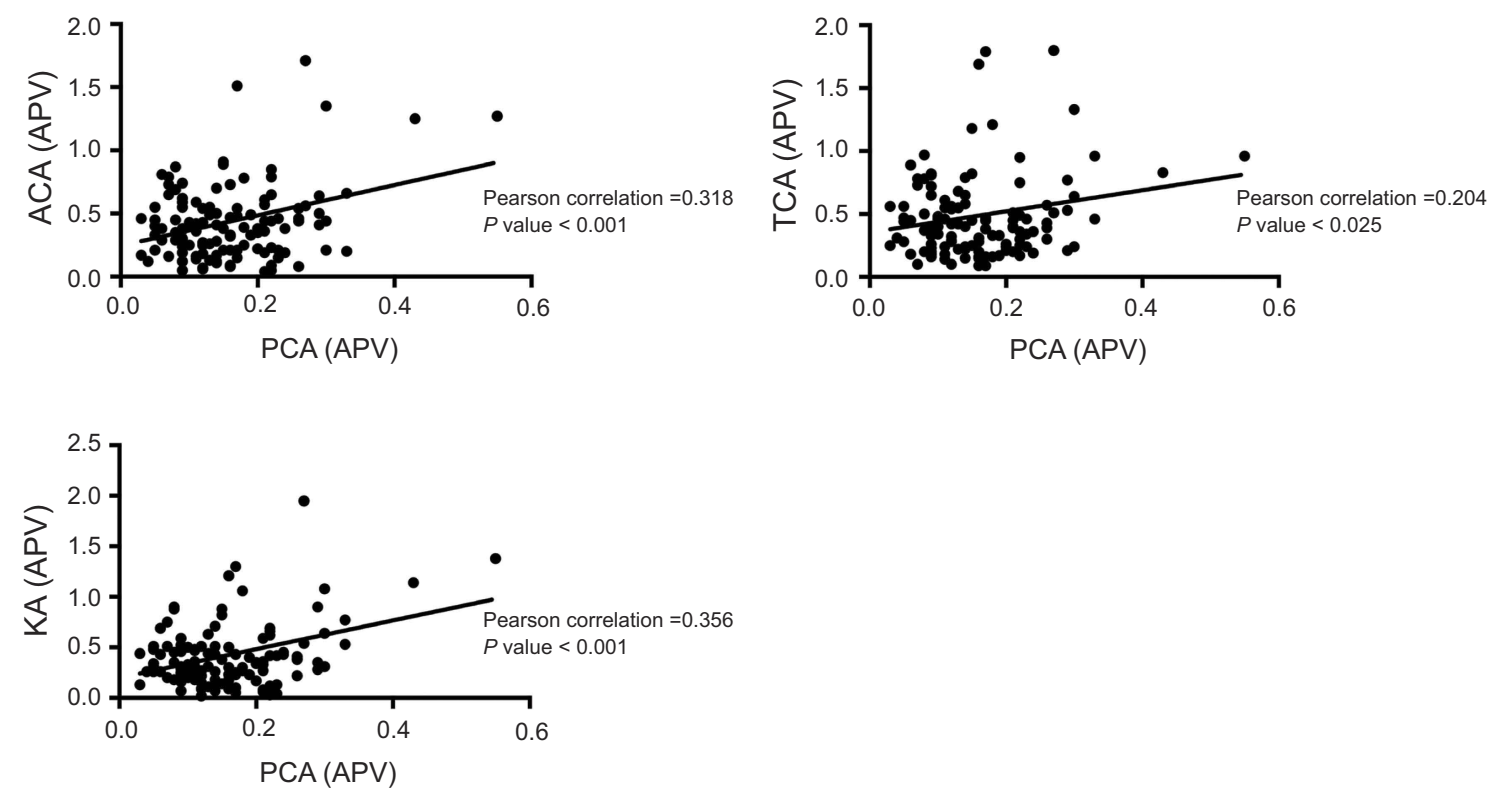

Figure 4 Positive linear correlations between the magnitude of ACA, TCA, KA and PCA.

Abbreviations: PCA, posterior corneal astigmatism; ACA, anterior corneal astigmatism; TCA, total corneal astigmatism; KA, simulated corneal astigmatism; APV, astigmatic power vector.

the main factor affecting aberration. In addition, pupil size is a factor that could affect visual function in eyes with refractive error, because of the amount of the aberrations, not only HOAs but also LOAs, are correlated with pupil diameter. Kamiya et $\mathrm{al}^{29}$ posit that the magnitude of astigmatism and pupil area size is a determining factor in uncorrected distance visual acuity (UDVA) in normal young phakic eyes. In vision systems with abnormalities (including both normal and pseudophakic eyes), optical quality is reduced in direct proportion to the diameter of the patients' pupils. Watanabe et $\mathrm{al}^{30}$ found that after cataract surgery, the postoperative UDVA was moderately negatively correlated in eyes with ATR astigmatism irrespective of the pupil size, and that UDVA was moderately negatively correlated in eyes with WTR astigmatism only when the pupils were large. Our study was performed using a $6.0 \mathrm{~mm}$ pupil scan diameter, which is widely used to evaluate optical aberrations. Senile miosis and lower defocus sensitivity in systems with ocular HOAs may mitigate such abnormalities. ${ }^{31}$ Pseudophakic eyes are expected to allow for better vision than phakic eyes due to the abnormalities being mitigated by smaller pupil diameters in older patients. ${ }^{31}$ In light of this finding, a wider range of IOL choices would be tolerated in elderly patients, allowing surgeons to consider safety factors and potential complications more carefully.
Studies have often focused on the effects of PCA on total astigmatism ${ }^{32-34}$ and Toric IOL previously. ${ }^{5,35}$ However, little is known about the influencing factors of PCA, especially the relationship between PCA and HOAs and $\mathrm{Q}$ value of cornea. Therefore, this study extensively focuses on PCA in Chinese cataract patients.

Some studies have found that the PCA of the cornea is $0.26-0.78$ in most corneas and the steep axis is located in the vertical diameter line, which produces reverse astigmatism. ${ }^{10,11} \mathrm{Koch}^{10}$ found that $9 \%$ of eyes had astigmatism $>0.50$ D. Jiang ${ }^{36}$ also found $87.04 \%$ eyes had PCA values $<0.5 \mathrm{D}, 12.96 \%$ eyes in Chinese cataract patients had PCA $\geq 0.5 \mathrm{D}$, ATR astigmatism predominated PCA (85.4\%). In this study, the posterior corneal surface astigmatism averaged $0.31 \pm 0.17 \mathrm{D}$, wherein $86.0 \%$ was ATRA, $8.30 \%$ was WTRA, and $85.9 \%$ presented PCA $<0.5 \mathrm{D}$, consistent with the preceding results, ${ }^{10,11,36}$ submitting a fairly stable PCA magnitude; direct measurement was not possible earlier, hence, our study essentially estimates TCA and PCA aspects, as do several other ongoing analyses, to supplement previous findings.

The current study found ACA and PCA to be significantly correlated; thus consistent with earlier studies again, ${ }^{10,37,38}$ PCA exhibited a strong positive correlation with KA and correlated weakly with TCA. These findings are vital to clinical practice and indicate high ACA values in eyes usually signify high PCA values as well, affecting 

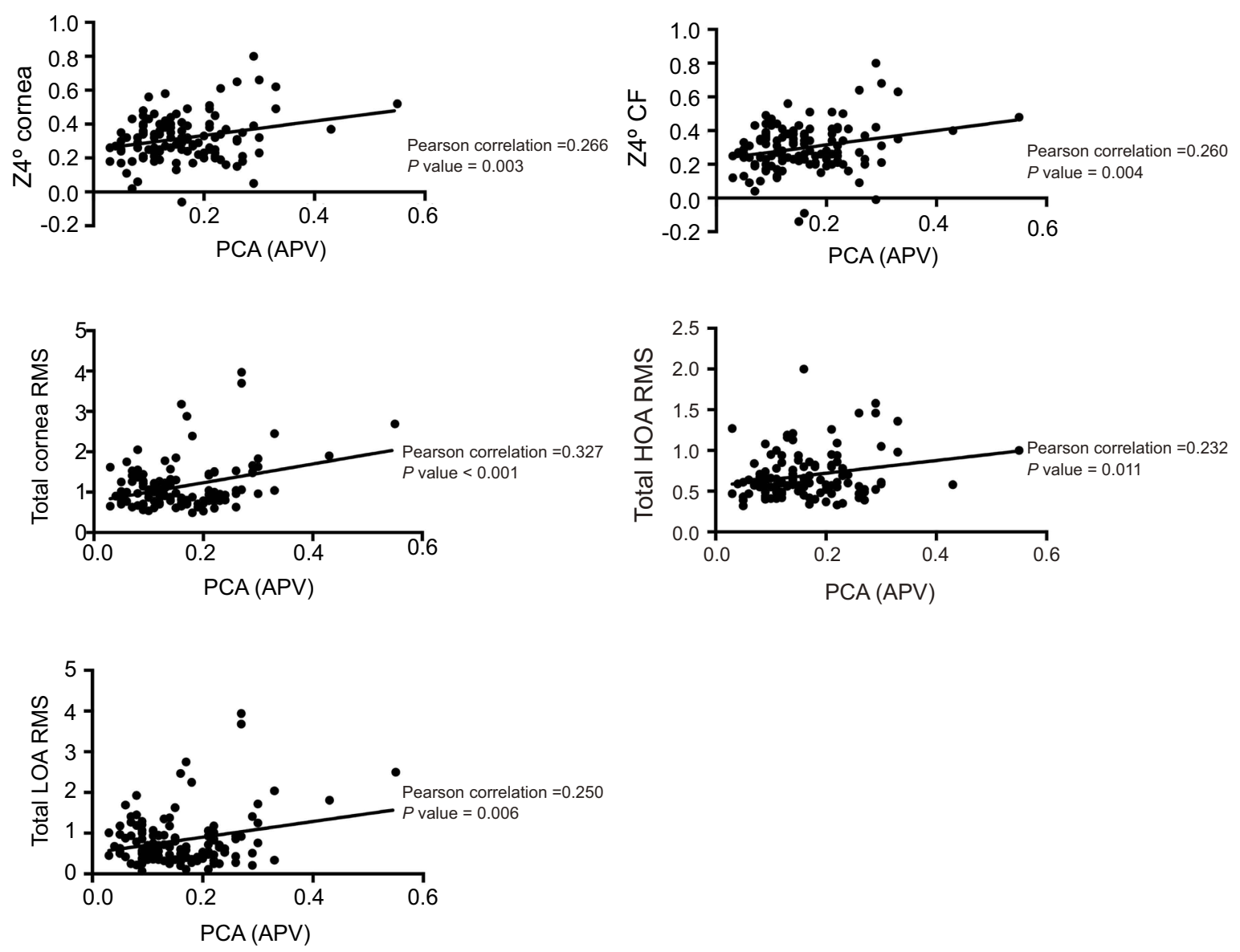

Figure 5 Positive linear correlations between the corneal aberration and PCA.

Abbreviations: $\mathrm{Z}^{\circ}$ cornea, primary spherical aberration of the total cornea; $\mathrm{Z} 4^{\circ} \mathrm{CF}$, primary spherical aberration of the corneal front surface; Total cornea RMS, total corneal aberrations; Total LOA RMS, total corneal lower-order aberrations; Total HOA RMS, total corneal higher-order aberrations; RMS, root mean square; APV, astigmatic power vector.

total corneal biometry. Therefore, when selecting IOL individually before cataract surgery, especially Toric IOL astigmatism evaluation, we should not only evaluate ACA, TCA or KA, but also include PCA in routine evaluation. For some primary hospitals without PCA instruments, it is suggested to observe ACA, TCA or KA to judge the magnitude of PCA. The relationship between them needs to be further studied for clinical application.

Previous studies have confirmed that corneal astigmatism is positively correlated with HOAs. ${ }^{39,40}$ It is also correlated with some components of corneal HOA, such as coma aberration and trefoil aberration. ${ }^{39,41}$ However, the relationship between PCA and corneal aberration has rarely been reported before. After analyzing the correlation between PCA and corneal aberration, we found that PCA was positively correlated with primary spherical aberration of the total cornea, primary spherical aberration of the corneal front, total corneal aberration, high-order corneal aberration and low-order corneal aberration (LOA).
However, it has no significant correlation with other components of HOAs such as coma aberration and trefoil aberration, which indicates that with the increase of PCA value, corneal spherical aberration, total corneal aberration, HOA and LOA will also increase, which may be related to the decrease of retinal imaging quality caused by HOA caused by astigmatism. ${ }^{42}$ Spherical aberration is the fourth-order HOA, which is the main aberration affecting vision in HOA of cornea. ${ }^{43}$ It is also the only axisymmetric HOA that can be corrected by IOL. ${ }^{44}$ At present, the application of aspheric IOL compensates the corneal spherical aberration and improves the visual function after cataract surgery. The visual quality of patients after surgery is mainly related to the residual aberration after implantation of aspheric IOL. ${ }^{45}$ Our results show that PCA is positively correlated with spherical aberration, suggesting that preoperative PCA assessment is also important for cataract patients to choose appropriate IOL. HOAs are closely related to visual quality, ${ }^{46,47}$ contrast 

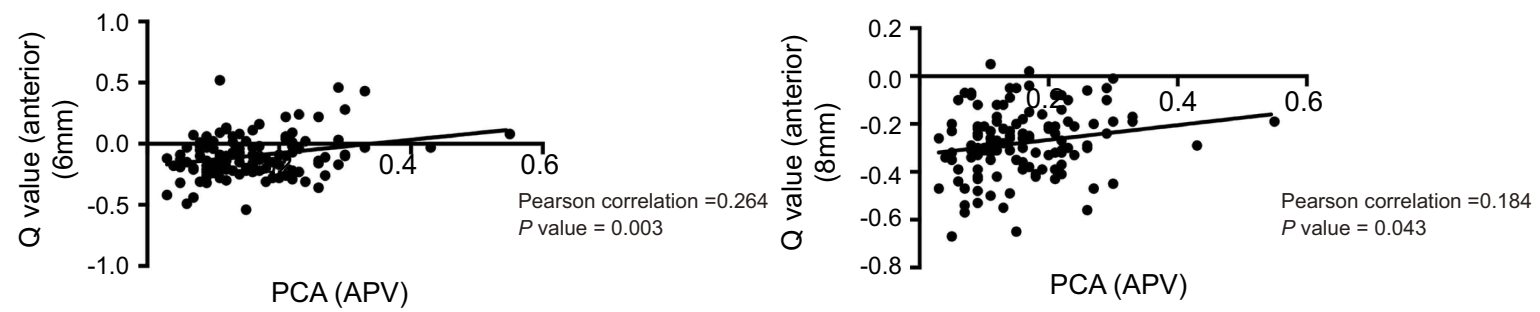

Figure 6 Positive linear correlations between the $Q$ value (anterior) and PCA. Abbreviations: PCA, posterior corneal astigmatism; APV, astigmatic power vector.

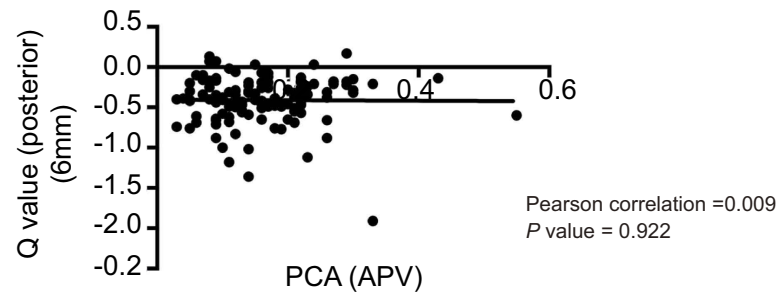

Figure 7 Correlations between the $\mathrm{Q}$ value (posterior) and PCA.

Abbreviations: PCA, posterior corneal astigmatism; APV, astigmatic power vector.

sensitivity, ${ }^{48}$ visual symptoms ${ }^{49}$ and visual efficacy. ${ }^{50}$ Our results show that PCA is correlated with HOA, especially spherical aberrations. Preoperative evaluation of PCA before cataract surgery will be of great significance to the recovery of visual function after surgery and to the better visual effect of patients.

The curvature of the anterior surface of normal cornea is different from the apex to the periphery, which belongs to aspheric surface. The non-spherical shape of cornea helps to reduce the aberration caused by light passing through the surrounding cornea when the pupil is dilated and improve the visual quality. At present, the aspheric coefficient of cornea ( $Q$ value) is commonly used to describe the changing trend of corneal curvature from the center to the periphery and to quantify the aspheric degree for comparison. ${ }^{51,52}$ Studies have shown that the effect of changes in Q value of cornea on HOAs may be one of the main causes of visual quality deterioration in some patients after corneal refractive surgery. ${ }^{53,54}$ Accordingly, Q-guided individualized keratectomy was proposed. According to different target $Q$ value of each patient, cornea is cut to keep the $\mathrm{Q}$ value of cornea relatively unchanged after surgery, reduce the HOA caused by surgery, and improve the visual quality of patients after surgery. ${ }^{55}$ Therefore, we studied the correlation between PCA and Q value of cornea and found that PCA was positively correlated with $Q$ value of anterior corneal surface under 6 and $8 \mathrm{~mm}$ pupil diameter, but not with $\mathrm{Q}$ value of posterior corneal surface. This result can be explained by the relationship between the $\mathrm{Q}$ value of cornea and the spherical aberration of anterior surface. Antonio $^{56}$ summarized the relationship between corneal anterior surface spherical aberration and corneal $Q$ value by using corneal model system. If the corneal refractive index and pupil diameter remain constant, the flatter the corneal surface (the smaller the Q value), the smaller the spherical aberration, and the steeper the corneal surface (the larger the $\mathrm{Q}$ value), the greater the spherical aberration. As previous studies have shown, PCA is mainly related to the anterior surface spherical aberration, but not to the posterior surface spherical aberration, so it is not difficult to understand that PCA is only related to the anterior surface corneal $\mathrm{Q}$ value. This result provides a theoretical basis for designing an aspheric artificial lens according to the $\mathrm{Q}$ value of cornea and improving the imaging quality.

Earlier studies established PCA had a weak negative correlation with age, and younger patients presented a higher mean PCA, as compared to the older ones. ${ }^{57}$ Nevertheless, further research submitted that, with increasing age, the posterior corneal surface usually remained the same, notably because of a relatively unchanged posterior steep meridian (a WTR to ATR shift marked the anterior and total meridians). ${ }^{10,45,58}$ In our study, no correlations were found between PCA and age, which may be related to the research population. Our study focused mainly on 

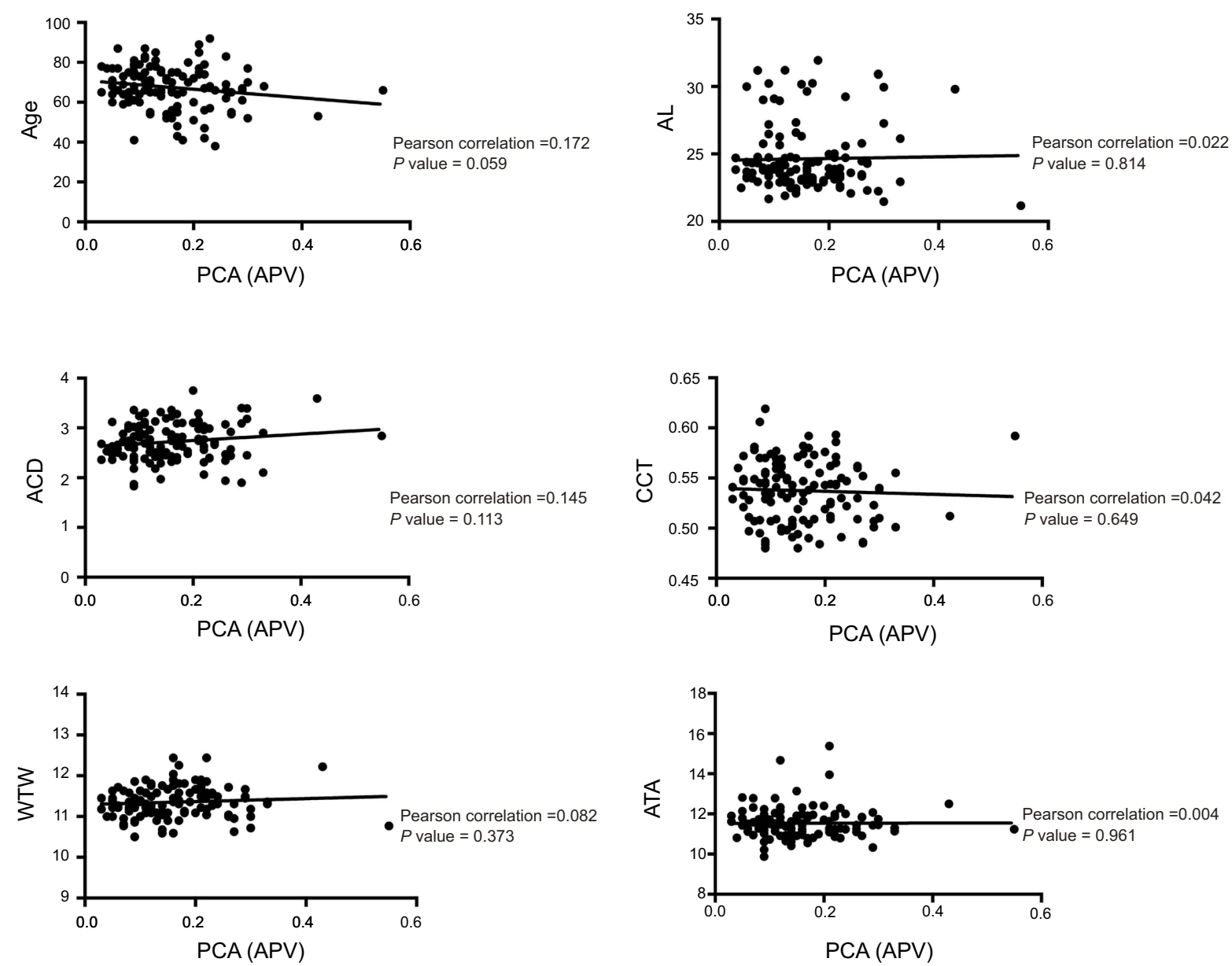

Figure 8 Correlations between Age, AL, ACD, CCT, WTW, ATA and PCA.

Abbreviations: PCA, posterior corneal astigmatism; AL, axial length; ACD, anterior chamber depth; CCT, central corneal thickness; WTW, horizontal corneal diameter; ATA, angle to angle distance; APV, astigmatic power vector.

middle-aged and the elderly, suggesting that PCA has little change in the middle-aged and the elderly cataract patients. Previous studies have found that there is no significant difference in the distribution of PCA values and astigmatism types between high myopia group and control group, which means that PCA values and astigmatism types are relatively stable, and will not change with the change of AL. In addition, Kaye ${ }^{58}$ found that although the total astigmatism of the eye is related to the myopia degree, the corneal astigmatism is not related to the myopia degree. Moreover, the increase of vitreous cavity length plays a major role in the development of myopia. ${ }^{59}$ These two points can explain why PCA does not change with AL. This study is consistent with previous studies in that no correlation between PCA and AL has been found.

In addition, this research also observed the relationship between PCA and ACD, CCT, WTW and ATA, which was rarely reported in previous studies, but PCA was not found to be significantly correlated with these factors. It shows that PCA degree is relatively stable, and these factors seems negligible when evaluating PCA.

The current study has some limitations. Firstly, our study sampled only a small number of patients, and secondly, we only deployed Sirius, results should have been confirmed via other corneal imaging techniques as well. Nevertheless, the device demonstrated exceptional repeatability, when measuring both corneal astigmatism, and aberrations.

\section{Conclusion}

In summary, our study showed that compared with ACA and TCA, the magnitude of PCA is small and most of them are ATR astigmatism. Posterior surface astigmatism is significantly and positively correlated with anterior surface astigmatism and total astigmatism. PCA is positively correlated with whole corneal spherical aberration, anterior 
surface Q value, anterior surface spherical aberration, whole corneal aberration, total high-order aberration and total loworder aberration, but not with age, AL, ACD, CCT, WTW and ATA. Consequently, clinical measurement of corneal astigmatism and IOL should essentially factor the corresponding aberration and Q value (front surface specifically).

\section{Ethics approval and informed consent}

The study protocol adhered to the tenets of the Declaration of Helsinki and was approved by the institutional review board of the First Affiliated Hospital of Soochow University. All patients signed an informed consent to allow the retrospective evaluation of their clinical data.

\section{Consent for publication}

Written informed consents were obtained to publish the details from each participant.

\section{Data availability}

Available upon request.

\section{Disclosure}

The authors report no conflicts of interest in this work.

\section{References}

1. Ferrer-Blasco T, Montes-Mico R, Peixoto-de-Matos SC, et al. Prevalence of corneal astigmatism before cataract surgery. $J$ Cataract Refract Surg. 2009;35(1):70-75. doi:10.1016/j.jcrs.2008.09.027

2. De Bernardo M, Zeppa L, Cennamo M, Iaccarino S, Zeppa L, Rosa N. Prevalence of corneal astigmatism before cataract surgery in Caucasian patients. Eur $J$ Ophthalmol. 2014;24(4):494-500. doi:10.5301/ejo.5000415

3. Chen W, Zuo C, Chen C, et al. Prevalence of corneal astigmatism before cataract surgery in Chinese patients. J Cataract Refract Surg. 2013;39(2):188-192. doi:10.1016/j.jcrs.2012.08.060

4. Yuan X, Song H, Peng G, et al. Prevalence of corneal astigmatism in patients before cataract surgery in Northern China. J Ophthalmol. 2014;2014:536412.

5. Koch DD, Jenkins RB, Weikert MP, Yeu E, Wang L. Correcting astigmatism with toric intraocular lenses: effect of posterior corneal astigmatism. J Cataract Refract Surg. 2013;39(12):1803-1809. doi:10.1016/j.jcrs.2013.06.027

6. Nemeth G, Berta A, Lipecz A, Hassan Z, Szalai E, Modis L. Evaluation of posterior astigmatism measured with Scheimpflug imaging. Cornea. 2014;33(11):1214-1218. doi:10.1097/ICO.000000000 0000238

7. Savini G, Versaci F, Vestri G, Ducoli P, Næser K. Influence of posterior corneal astigmatism on total corneal astigmatism in eyes with moderate to high astigmatism. $J$ Cataract Refract Surg. 2014;40 (10):1645-1653. doi:10.1016/j.jcrs.2014.01.046

8. Koch DD, Ali SF, Weikert MP, Shirayama M, Jenkins R, Wang L. Contribution of posterior corneal astigmatism to total corneal astigmatism. J Cataract Refract Surg. 2012;38(12):2080-2087. doi:10. 1016/j.jcrs.2012.08.036
9. Savini G, Næser K. An analysis of the factors influencing the residual refractive astigmatism after cataract surgery with toric intraocular lenses. Invest Ophthalmol Vis Sci. 2015;56(2):827-835. doi:10. 1167/iovs. 14-15903

10. Gundersen KG, Potvin R. Clinical outcomes with toric intraocular lenses planned using an optical low coherence reflectometry ocular biometer with a new toric calculator. Clin Ophthalmol. 2016;10:2141-2147. doi:10.2147/OPTH.S120414

11. Ho JD, Tsai CY, Liou SW. Accuracy of corneal astigmatism estimation by neglecting the posterior corneal surface measurement. $\mathrm{Am} \mathrm{J}$ Ophthalmol. 2009;147(5):788-795. doi:10.1016/j.ajo.2008.12.020

12. Finis D, Ralla B, Karbe M, Borrelli M, Schrader S, Geerling G. Comparison of two different Scheimpflug devices in the detection of keratoconus, regular astigmatism, and healthy corneas. $J$ Ophthalmol. 2015;2015:315281. doi:10.1155/2015/315281

13. Wang X, Wu Q. Investigation of the human anterior segment in normal Chinese subjects using a dual Scheimpflug analyzer. Ophthalmology. 2013;120(4):703-708. doi:10.1016/j.ophtha.2012.09.034

14. Prasad A, Fry K, Hersh PS. Relationship of age and refraction to central corneal thickness. Cornea. 2011;30(5):553-555. doi:10.1097/ ICO.0b013e $3181 \mathrm{fb} 880 \mathrm{c}$

15. Masoud M, Livny E, Bahar I. Repeatability and intrasession reproducibility obtained by the Sirius anterior segment analysis system. Eye Contact Lens. 2015;41:107-110. doi:10.1097/ICL.0000000000000074

16. Hernandez-Camarena JC, Chirinos-Saldana P, Navas A, et al. Repeatability, reproducibility, and agreement between three different Scheimpflug systems in measuring corneal and anterior segment biometry. J Refract Surg. 2014;30(9):616-621. doi:10.3928/1081 597X-20140815-02

17. Savini G, Barboni P, Carbonelli M, Hoffer KJ. Repeatability of automatic measurements by a new Scheimpflug camera combined with Placido topography. J Cataract Refract Surg. 2011;37 (10):1809-1816. doi:10.1016/j.jcrs.2011.04.033

18. Savini G, Carbonelli M, Sbreglia A, Barboni P, Deluigi G, Hoffer KJ. Comparison of anterior segment measurements by 3 Scheimpflug tomographers and 1 Placido corneal topographer. $J$ Cataract Refract Surg. 2011;37(9):1679-1685. doi:10.1016/j.jcrs.2011.03.055

19. Thibos LN, Horner D. Power vector analysis of the optical outcome of refractive surgery. J Cataract Refract Surg. 2001;27:80-85. doi:10.1016/S0886-3350(00)00797-5

20. Read SA, Collins MJ. Diurnal variation of corneal shape and thickness. Optom Vis Sci. 2009;86(3):170-180. doi:10.1097/OPX.0b0 $13 \mathrm{e} 3181 \mathrm{~b} 4 \mathrm{c} 4 \mathrm{~d} 9$

21. Dunne MC, Royston JM, Barnes DA. Posterior corneal surface toricity and total corneal astigmatism. Optom Vis Sci. 1991;68 (9):708-710. doi:10.1097/00006324-199109000-00006

22. Dubbelman M, Sicam VA, Van der Heijde GL. The shape of the anterior and posterior surface of the aging human cornea. Vision Res. 2006;46(6-7):993-1001. doi:10.1016/j.visres.2005.09.011

23. Montalban R, Pinero DP, Javaloy J, Alió JL. Scheimpflug photography-based clinical characterization of the correlation of the corneal shape between the anterior and posterior corneal surfaces in the normal human eye. J Cataract Refract Surg. 2012;38(11):19251933. doi:10.1016/j.jcrs.2012.06.050

24. Tonn B, Klaproth OK, Kohnen T. Anterior surface-based keratometry compared with Scheimpflug tomography-based total corneal astigmatism. Invest Ophthalmol Vis Sci. 2014;56(1):291-298. doi:10.1167/ iovs.14-15659

25. Zhang L, Sy ME, Mai H, Yu F, Hamilton DR. Effect of posterior corneal astigmatism on refractive outcomes after toric intraocular lens implantation. J Cataract Refract Surg. 2015;41(1):84-89. doi:10.1016/j.jcrs.2014.04.033

26. Nasser CK, Singer R, Barkana Y, Zadok D, Avni I, Goldich Y. Repeatability of the Sirius imaging system and agreement with the Pentacam HR. J Refract Surg. 2012;28(7):493-497. doi:10.3928/ 1081597X-20120619-01 
27. Lanza M, Iaccarino S, Cennamo M, Lanza A, Coen G. New Scheimpflug camera device in measuring corneal power changes after myopic laser refractive surgery. Cont Lens Anterior Eye. 2015;38(2):115-119. doi:10.1016/j.clae.2014.12.003

28. Miyagawa S, Mihashi T, Kanda H, et al. Asymmetric wavefront aberrantions and pupillary shapes induced by electrical stimulateon of ciliary nerve in cats measured with compact wavefront aberrometer. PLoS One. 2014;9(8):e105615. doi:10.1371/journal.pone.0105615

29. Kamiya K, Kobashi H, Shimizu K, Kawamorita T, Uozato H. Effect of pupil size on uncorrected visual acuity in astigmatic eyes. $\mathrm{Br} J$ Ophthalmol. 2012;96(4):267-270. doi:10.1136/bjo.2011.202481

30. Watanabe K, Negishi K, Dogru M, Yamaguchi T, Torii H, Tsubota K. Effect of pupil size on uncorrected visual acuity in pseudophakic eyes with astigmatism. J Refract Surg. 2013;29(1):25-29. doi:10.3928/ 1081597X-20121106-03

31. Iseli HP, Jankov M, Bueeler M, Wimmersberger Y, Seiler T, Mrochen M. Corneal and total wavefront aberrations in phakic and pseudophakic eyes after implantation of monofocal foldable intraocular lenses. J Cataract Refract Surg. 2006;32:762-771. doi:10.1016/j. jcrs.2005.10.032

32. Jin YY, Zhou Z, Yuan XY, et al. Effect of the posterior corneal surface on total corneal astigmatism in patients with age-related cataract. Int $J$ Ophthalmol. 2018;11(6):958-965. doi:10.18240/ ijo.2018.02.21

33. Read SA, Vincent SJ, Collins MJ. The visual and functional impacts of astigmatism and its clinical management. Ophthalmic Physiol Opt. 2014;34(3):267-294. doi:10.1111/opo.12128

34. Eom Y, Kang SY, Kim HM, et al. The effect of posterior corneal flat meridian and astigmatism amount on the total corneal astigmatism estimated from anterior corneal measurements. Graefes Arch Clin Exp Ophthalmol. 2014;252(11):1769-1777. doi:10.1007/s00417-013-2540-z

35. Reitblat O, Levy A, Kleinmann G, Abulafia A, Assia EI. Effect of posterior corneal astigmatism on power calculation and alignment of toric intraocular lenses: comparison of methodologies. J Cataract Refract Surg. 2016;42(2):217-225. doi:10.1016/j.jcrs.2015.11.036

36. Jiang Y, Tang Y, Jing Q, Qian D, Lu Y. Distribution of posterior corneal astigmatism and aberration before cataract surgery in Chinese patients. Eye. 2018;32(12):1831-1838. doi:10.1038/s41433-018-0186-0

37. Miyake T, Shimizu K, Kamiya K. Distribution of posterior corneal astigmatism according to axis orientation of anterior corneal astigmatism. PLoS One. 2015;10(1):e0117194. doi:10.1371/journal.pone.0117194

38. Naderan M, Rajabi MT, Zarrinbakhsh P. Distribution of anterior and posterior corneal astigmatism in eyes with keratoconus. Am J Ophthalmol. 2016;167:79-87. doi:10.1016/j.ajo.2016.03.051

39. Zhou Z, Zhang FJ. Analysis of characteristic and effective factors of corneal aberrations in myopic astigmatic eyes. Chin J Praet Ophthalmol. 2009;27(7):718-721.

40. Li X, Wang Y, Zhang L. Change of higher order aberration after 2 $\mathrm{mm}$ micro-incision SMILE in myopia. Chin J Exp Ophthalmol. 2015;33(2):142-148.

41. Wei RH, Lim L, Chan WK, et al. Higher order ocular aberrations in eyes with myopia in a Chinese population. J Refract Surg. 2006;22 (7):695-702. doi:10.3928/1081-597X-20060901-11

42. Xu LL, Wang Y, Wu YN. Assessment of corneal optical quality following small incision lenticule extraction for myopia. Chin J Exp Ophthalmol. 2017;35(2):139-145.
43. Guirao A, Artal P. Corneal wave aberration from video keratography: accuracy and limitations of the procedure. J Opt Soc Am A Opt Image Sci Vis. 2000;17(6):955-965.

44. Holladay JT, Piers PA, Koranyi G, et al. A new intraocular lens design to reduce spherical aberration of pseudo phakic eyes. $J$ Refract Surg. 2002;18(6):683-691.

45. Beiko GH. Personalized correction of spherical aberration in cataract surgery. J Cataract Refract Surg. 2007;33(8):1455-1460. doi:10.1016/j.jcrs.2007.04.019

46. Guirao A, Porter J, Williams DR, et al. Calculated impact of higherorder monochromatic aberrations on retinal image quality in a population of human eyes. J Opt Soc Am A Opt Image Sci Vis. 2002;19 (1):1-9.

47. Yoon GY, Williams DR. Visual performance after correcting the monochromatic and chromatic aberrations of the eye. J Opt Soc Am A Opt Image Sci Vis. 2002;19(2):266-275.

48. Yoon G, Jeong TM, Cox IG, et al. Vision improvement by correcting higher-order aberrations with phase plates in normal eyes. $J$ Refract Surg. 2004;20(5):S523-527.

49. Chalita MR, Chavala S, Xu M, et al. Wavefront analysis in postLASIK eyes and its correlation with visual symptoms, refraction, and topography. Ophthalmology. 2004;111(3):447-453. doi:10.1016/j. ophtha.2004.04.014

50. Applegate RA, Sarver EJ, Khemsara V. Are all aberrations equal? $J$ Refract Surg. 2002;18(5):S556-562.

51. Davis WR, Raasch TW, Mitchell GL, Mutti DO, Zadnik K. Corneal asphericity and apical curvature in children: a cross-sectional and longitudinal evaluation. Invest Ophthalmol Vis Sci. 2005;46 (6):1899-1906. doi:10.1167/iovs.04-0558

52. Atchison DA, Smith G. Chapter 2 - Refracting components: cornea and lens. In: Atchison DA, Smith G, editors. Optics of the Human Eye. Edinburgh: Butterworth-Heinemann; 2000:11-20.

53. Tan G, Chen X, Xie RZ, et al. Reverse geometry rigid gas permeable contact lens wear reduces high-order aberrations and the associated symptoms in post-LASIK patients. Curr Eye Res. 2010;35(1):9-16. doi:10.3109/02713680903421186

54. Tan G, Yang J, Chen X, He H, Zhong X. Changes in wave-front aberrations after rigid gas permeable contact lens fitting in post-laser in situ keratomileusis patients with visual complaints. Can J Ophthalmol. 2010;45(3):264-268. doi:10.3129/i09-268

55. Mastropasqua L, Toto L, Zuppardi E, et al. Photorefractive keratectomy with aspheric profile of ablation versus conventional photorefractive keratectomy for myopia correction: six-month controlled clinical trial. J Cataract Refract Surg. 2006;32(1):109-116. doi:10.1016/j.jcrs.2005.11.026

56. Calossi A. Corneal asphericity and spherical aberration. J Refract Surg. 2007;23(5):505-514. doi:10.3928/1081-597X-20070501-15

57. Ho JD, Liou SW, Tsai RJ, Tsai C-Y. Effects of aging on anterior and posterior corneal astigmatism. Cornea. 2010;29(6):632-637. doi:10.1097/ICO.0b013e3181c2965f

58. Kaye SB, Patterson A. Association between total astigmatism and myopia. J Cataract Refract Surg. 1997;23(10):1496-1502. doi:10.1016/S0886-3350(97)80020-X

59. Goh WS, Lam CS. Changes in refractive trends and optical components of Hong Kong Chinese aged 19-39 years. Ophthalmic Physiol Opt. 1994;14(4):378-382. doi:10.1111/j.1475-1313.1994.tb00128.x 


\section{Supplementary material}

Table SI Correlations between PCA and influencing factors

\begin{tabular}{|c|c|c|c|}
\hline PCA (APV) & $R$ & $R^{2}$ & $P$ \\
\hline Age & -0.172 & 0.030 & 0.059 \\
\hline $\mathrm{AL}$ & 0.022 & 0.000 & 0.814 \\
\hline$A C D$ & 0.145 & 0.021 & 0.113 \\
\hline CCT & -0.042 & 0.002 & 0.649 \\
\hline WTW & 0.082 & 0.007 & 0.373 \\
\hline ATA & 0.004 & 0.000 & 0.961 \\
\hline $\mathrm{Z3}^{1,-1}$ cornea & 0.156 & 0.024 & 0.088 \\
\hline $\mathrm{Z3}^{3,-3}$ cornea & 0.112 & 0.012 & 0.223 \\
\hline $\mathrm{Z}^{1,-1} \mathrm{CF}$ & 0.161 & 0.026 & 0.078 \\
\hline $\mathrm{Z3}^{3,-3} \mathrm{CF}$ & 0.085 & 0.007 & 0.356 \\
\hline $\mathrm{Z}^{1,-1} \mathrm{CB}$ & 0.015 & 0.000 & 0.867 \\
\hline $\mathrm{Z3}^{3,-3} \mathrm{CB}$ & -0.036 & 0.001 & 0.693 \\
\hline $\mathrm{Z} 4^{\circ} \mathrm{CB}$ & -0.004 & 0.000 & 0.966 \\
\hline $\mathrm{Q}$ value (posterior $6 \mathrm{~mm}$ ) & -0.009 & 0.000 & 0.922 \\
\hline $\mathrm{Q}$ value (posterior $8 \mathrm{~mm}$ ) & 0.029 & 0.001 & 0.754 \\
\hline
\end{tabular}

Abbreviations: PCA, posterior corneal astigmatism; AL, axial length; ACD, anterior chamber depth; CCT, central corneal thickness; WTW, horizontal corneal diameter; ATA, angle to angle distance; APV, astigmatic power vector.

\section{Publish your work in this journal}

Clinical Ophthalmology is an international, peer-reviewed journal covering all subspecialties within ophthalmology. Key topics include: Optometry; Visual science; Pharmacology and drug therapy in eye diseases; Basic Sciences; Primary and Secondary eye care; Patient Safety and Quality of Care Improvements. This journal is indexed on PubMed
Central and CAS, and is the official journal of The Society of Clinical Ophthalmology (SCO). The manuscript management system is completely online and includes a very quick and fair peer-review system, which is all easy to use. Visit http://www.dovepress.com/ testimonials.php to read real quotes from published authors. 